\title{
Toward Learning from Change Pathways: Reviewing Theory of Change and Its Discontents
}

\author{
Steven Lam \\ Independent Consultant
}

\begin{abstract}
The concept of Theory of Change (ToC) is well established in the evaluation literature, underpinning substantial research and practice efforts. However, its ability to facilitate learning has been increasingly debated. The objective of this paper is to identify, characterize, and evaluate concerns over the use of ToCs based on a review of relevant studies. Seven concerns are found: distinguishing ToCs from other evaluation approaches, conceptual vagueness, under-developed ToCs, undercontribution to theoretical knowledge, uncertainty in stakeholder engagement, neglecting context, and overlooking complexity. Priority areas for improvement include integrating context and complexity throughout the ToC process, contributing theoretical knowledge, and engaging stakeholders as appropriate.
\end{abstract}

Keywords: impact pathway, logic model, program theory, research on evaluation, theory-driven evaluation, theory of change

Résumé : La théorie du changement (TdC) est bien connue dans le domaine de lévaluation et soutient la recherche et la pratique. Cependant, sa capacité à faciliter l'apprentissage fait de plus en plus l'objet de débats. L'objectif du présent article est de noter, de décrire et dévaluer les préoccupations liées à l'utilisation d'une TdC, à la lumière d'un examen de projets de recherche pertinents. Sept préoccupations se sont dégagées de létude: différencier la TdC d’autres approches dévaluation, le flou conceptuel, le manque de développement de certaines TdC, le manque de contribution aux connaissances théoriques, l'incertitude quant au degré d'engagement des parties prenantes, loubli du contexte et une sous-estimation de la complexité des tâches. Les améliorations prioritaires devraient porter sur l'intégration du contexte et de la complexité tout au long du processus de la TdC, l'apport de connaissances théoriques et lengagement des parties prenantes, le cas échéant.

Mots clés : Cheminement d'impact, modèle de logique, théorie des programmes, recherche en évaluation, évaluation fondée sur la théorie, théorie du changement

Theories of Change (ToCs) are becoming a mainstream approach to evaluation (Maru et al., 2018; Stein \& Valters, 2012; Valters, 2015; Vogel, 2012). Originally developed by Carol Weiss (1995), a ToC describes and shows how and why an initiative works. In the early 2010s, the latter part of this definition was expanded

Corresponding author: Steven Lam, 68 Bowen Drive, Guelph, ON N1E 7M2; email: lams@ uoguelph.ca 
to include in what context an initiative works (James, 2011). The ToC process can begin by identifying the long-term goal of an initiative; then, working backward, the causal linkages between the goal and outcomes are established (Figure 1). Afterward, the assumptions underlying these linkages and the contextual factors in which an initiative is situated are determined. Done collaboratively, a ToC helps stakeholders predict, test, and explain change, thus serving as a useful framework for monitoring and evaluation.

ToC research and practice remain prominent in health, sociology, and international development fields. However, ToCs have come under increasing scrutiny in recent years, with some questioning the ability of $\mathrm{ToC}$ to facilitate learning, consider context, and capture complexity (Ghate, 2018; Maini, Mounier-Jack, \& Borghi, 2018; Moore \& Evans, 2017). And, since the publication of several notable reviews on the ToC approach (Breuer, Lee, De Silva, \& Lund, 2016; James, 2011; Stein \& Valters, 2012; Vogel, 2012), few have examined the conceptual, epistemological, and methodological concerns facing ToC research and practice. Understanding and addressing these concerns are important for establishing the potential of the ToC approach.

The objective of this article is to identify, characterize, and evaluate concerns over the use of ToC in evaluation, based on a review of studies that report on, critique, or comment on ToCs. Seven concerns are identified and evaluated in light of the evaluation literature. I use this review to examine some of the ToC concerns, suggesting solutions and key directions for future work in moving ToC research and practice forward. I hope this discussion stimulates further conversation on

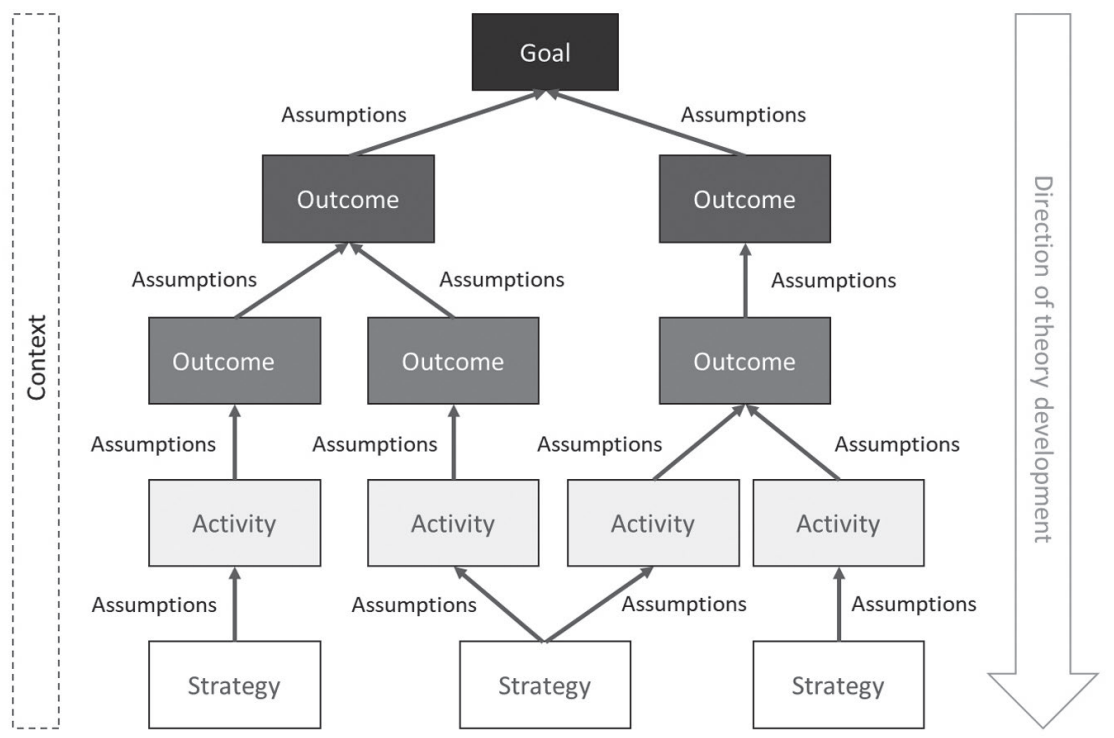

Figure 1. Generic Theory of Change map 
Table 1. Assessment tool for evaluating evidence supporting or countering the concerns

\begin{tabular}{ll} 
Strength of evidence & Description \\
\hline Limited & $\begin{array}{c}\text { Fewer studies explicitly or implicitly reporting on the concern } \\
\text { than studies with evidence countering the concern } \\
\text { Studies provide no or limited justifications for the concern } \\
\text { Partially supported } \\
\text { compared to studies with evidence countering the concern } \\
\text { Adequate justifications both supporting and countering the } \\
\text { concern are presented in the studies } \\
\text { More studies explicitly or implicitly reporting on the concern } \\
\text { than studies with evidence countering the concern } \\
\text { Studies provide adequate justifications for the concern }\end{array}$ \\
\hline
\end{tabular}

how ToCs, or alternative approaches to evaluation, can support the learning of stakeholders about pathways toward change.

\section{METHODS}

The keyword "Theory of Change" was used to search the citation database Web of Science ${ }^{\mathrm{Tm}}$ CORE Collection. This search was complemented by a search in Google Scholar using the same keyword. Only the first 200 hits of Google Scholar were screened for inclusion. To be included, studies had to be published in a journal or report, describe the use of a ToC, and report on a concern related to ToC. Information extracted from the study included the year of publication, type of study, and sector focus. After an in-depth reading of each study, studies were coded for reported challenges associated with ToCs. Challenges had to address conceptual, epistemological, or methodological considerations specific to ToC to be classified as a concern; challenges such as limited time, resources, and data were noted in many studies but reflect broader challenges not specific to ToC and were thus excluded. Furthermore, concerns had to be present in at least three studies to be included. All studies were then re-read and assessed to determine whether evidence supporting and countering the concern was reported. Evidence was evaluated along a three-point scale: limited, partly supported, and supported (Table 1). Seven concerns were repeatedly noted across studies, and these form the corpus of concerns addressed here. Of note, this review is not exhaustive but rather is intended to be broadly representative of the major concerns in the literature on $\mathrm{ToC}$ use.

\section{RESULTS}

A total of 45 studies meeting the inclusion criteria were reviewed. Most (73\%, $n=33)$ were published within the past five years (2015 -2019). The review included 
several different types of studies, including case studies $(53 \%, n=24)$, reviews $(22 \%, n=10)$, and opinion pieces $(25 \%, n=11)$. Social change was the main sector of focus $(25 \%, n=11)$, followed by food, agriculture, and nutrition $(18 \%, n=8)$, public health $(11 \%, n=5)$, health care $(11 \%, n=5)$, community development $(\mathrm{n}=11 \%, n=5)$, education $(2 \%, n=1)$, and climate change adaptation $(2 \%, n=1)$. Seven concerns were identified from the review of the literature, which speaks to the challenges and limitations of using ToC in evaluation (Table 2).

\section{Concern 1: Distinguishing ToCs from other evaluation approaches}

One common concern across the reviewed papers was what precisely a ToC is and how it differs from other evaluation approaches, particularly logic models and logical frameworks (DuBow \& Litzler, 2019; Freer \& Lemire, 2019; Maini et al., 2018; Maru et al., 2018; Nkwake, 2013).

\section{Limited evidence}

Many studies articulated the relationship, similarities, and differences between ToC and other approaches (De Silva et al., 2014; Omore et al., 2019; Prinsen \& Nijhof, 2015). For example, De Silva et al. (2014) suggested that logic models and frameworks present a simplified model of action in a rigid linear way that articulates inputs, activities, and outcomes but that does not make explicit how or why they are linked; while these approaches are suitable for program monitoring and evaluation, they are less useful for understanding the mechanisms of change underlying the program. Conversely, ToCs focus on pathways linking activities to outcomes and how these relate to one another causally. In doing so, ToCs outline the mechanisms of change as well as the assumptions that support or hinder the change pathway. Essentially, a ToC is one of many evaluation tools that can be used as an alternative, in parallel to, or in integration with other approaches (DuBow \& Litzler, 2019; Freer \& Lemire, 2019; Maini et al., 2018).

\section{Concern 2: Conceptual vagueness}

The use of the word "theory" in a ToC can be misleading, as theory implies "a set of concepts and/or statements with specification of how phenomena relate to each other," providing "an organizing description of a system that accounts for what is known, and explains and predicts phenomena" (Davis, Campbell, Hildon, Hobbs, \& Michie 2015, p. 327). Yet such theory is not applied in a ToC but rather is produced by an initiative and its stakeholders.

\section{Partially supported evidence}

Conceptual vagueness has led to misunderstandings about the distinction between ToCs and social science theories derived from research in a particular field (DuBow \& Litzler, 2019; Stein \& Valters, 2012). De Silva et al. (2014, p. 2) suggest that "ToC is not a sociological or psychological theory such as Complexity Theory or the Theory of Planned Behaviour, but a pragmatic framework which describes how the intervention affects change." While not a theory itself, a ToC can be strengthened by drawing on social science theories at key points to explain 


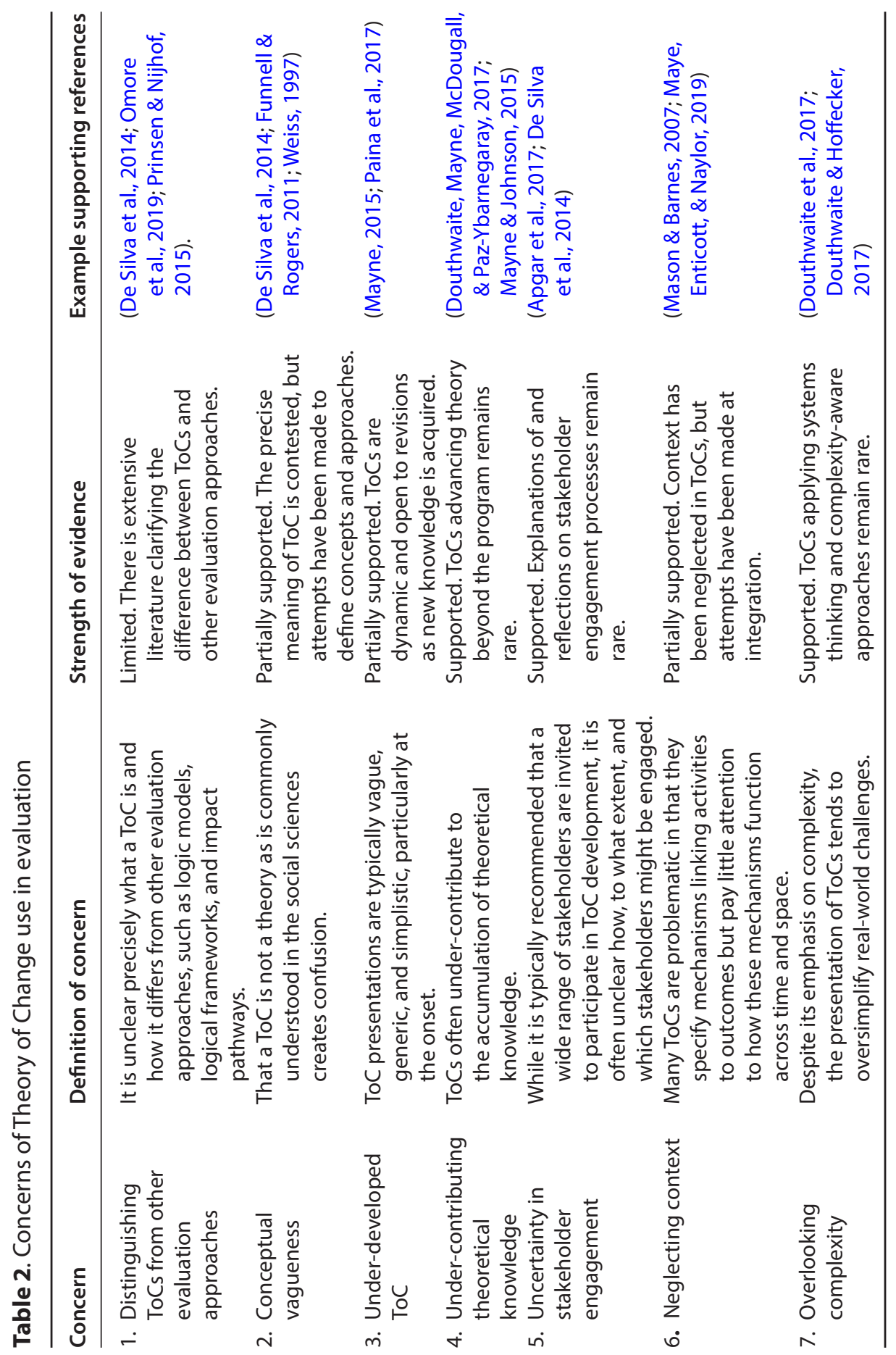


why particular links happen (De Silva et al., 2014; Stein \& Valters, 2012; Weiss, 1997). By focusing attention on the theoretical underpinnings of program design (Amundsen \& D’Amico, 2019), ToCs might be considered middle-range theories; they are influenced by more abstract theory but they aim to explain limited sets of phenomena about a program (Nilsen, 2015).

Several authors also distinguish between ToCs and theories of action (or implementation theory according to Weiss, 1997). In this context, ToCs refer to how endogenous change happens in the social, political, and economic system; in other words, change happens with or without programs. Theories of action are the ways in which programs are constructed that help activate these ToCs (Funnell \& Rogers, 2011; Green, 2017; Hivos, 2015). Together they form the program theory. From this distinction, it is possible that many ToCs have conflated the two and, in turn, overestimated their importance. As such, a ToC should articulate both theories of how systems change occurs and theories of how programming will trigger these changes (Hivos, 2015).

While there is little consensus about its precise meaning, there is an agreement that ToC denotes an exploration of why, how, and in what context an initiative works. Some view that conceptual vagueness hampers learning, comparative analyses, and syntheses, calling for practitioners to adopt specific definitions (e.g. De Silva et al., 2014). However, the diversity of ToC understandings might be considered an indicator of its strength, opening up space for exploration, innovation, and adaptation. In this view, rather than striving for a unified definition of ToC, practitioners should be aware of the diverse meanings, purposes, and outcomes that exist and be explicit about the conceptualizations that they use. ${ }^{1}$

\section{Concern 3: Under-developed ToC}

ToCs were critiqued for being vague, generic, and simplistic, particularly at the onset (Belcher, Suryadarma, \& Halimanjaya, 2017; James, 2011; Vogel, 2012). Such critiques were also noted more than 20 years ago: "Evaluators are currently making do with the assumptions that they are able to elicit from program planners and practitioners or which the logical reasoning that they bring to the table. Many of these theories are elementary, simplistic, partial, or even outright wrong" (Weiss, 1997, p. 51). And without an emphasis on process and learning, ToCs risk becoming a tool that fails to foster learning and reflection (Valters, 2015).

\section{Partially supported evidence}

There is no prescribed process for conducting a ToC (Connell \& Kubisch, 1998; Mason \& Barnes, 2007; Vogel, 2012). Rather, many authors viewed that ToC processes are best kept flexible (Vogel, 2012; Omore et al., 2019). Yet perhaps given their flexible nature, ToCs tend to be under-developed. For instance, it is not uncommon for ToCs to miss key steps such as outlining the assumptions, considering the context, or describing the nature of causal connections (Davies, 2018). And in some recently published cases, assumptions appeared to be left out entirely (Makowiecka et al., 2019; Sarma et al., 2019; Thompson \& Moret, 2019). 
Assumptions are statements of how and why change happens; they can be made about the events or conditions necessary for a particular link to be realized (i.e., causal link assumption) or about why a precondition is necessary to move from outcome to outcome (i.e., rationale assumption) (Archibald, Sharrock, Buckley, \& Cook, 2016; Mayne, 2017). Considering that assumptions are based on ideas, hypotheses, values, and worldviews of stakeholders, articulating them becomes challenging. ToCs might also be based on weak and selected evidence bases, creating a misleading sense of security about the level of critical analysis a program has been subjected to (Valters, 2015). Nevertheless, ToCs may be developed over time as implementation enables the linkages between action and outcomes to be better understood. Indeed, one study exploring ToCs in a health systems context reflected, "the first ToCs could not initially account for all the systems complexities and the project team could not anticipate all of the contextual changes" (Paina et al., 2017, p. 34). The authors added that ToC revision processes helped facilitate learning from implementation.

\section{Concern 4. Under-contribution to theoretical knowledge}

ToCs often under-contribute to the cumulation of theoretical knowledge (Moore \& Evans, 2017; Rolfe, 2019; Weiss, 1997).

\section{Supported evidence}

That "theories" are made explicit and therefore testable in ToCs enables ToCs to contribute to the development of theory; doing so will inform strategies for implementing programs in different contexts (Douthwaite et al., 2017). ToCs can support individual-level theorizing; for example, while each program as a whole is unique, activities such as knowledge translation, policy advocacy, and research can trigger mechanisms of change that might be shared across different programs. Developing such shared mechanisms of change is especially important given the limited evidence base on the effectiveness of intervention components (Rolfe, 2019). ToCs can also contribute to knowledge disconfirming or confirming middle-range theories; according to Pawson (2013), all evaluations operate within a common set of ToCs, each inquiry capable of adding to and refining a recyclable conceptual framework. And at the other end of the spectrum, ToCs can support a broader conceptualization of theory; moving beyond middle-range theorizing is important if a theory is "to enhance, rather than constrain, the contribution of intervention research" (Moore \& Evans, 2017, p. 134). Grand theories can be developed through testing overarching theoretical assumptions or mechanisms of change.

\section{Concern 5. Uncertainty in stakeholder engagement}

It is typically recommended that a wide range of stakeholders be invited to participate in ToC development. However, it is often unclear how, to what extent, and which stakeholders might be engaged (Forsyth, 2018; Stein \& Valters, 2012; Valters, 2015), and the implications of these on ToCs processes and outcomes. 
Two approaches are often suggested: either bring stakeholders together and build the ToC from the beginning, or have a small group build a draft $\mathrm{ToC}$ and then engage a wider group in reviewing, critiquing, and revising the draft (Mayne, 2015). Yet, applying ToC in an agricultural systems context, Apgar et al. (2017, p. 28) reported difficulties in "bringing new and unexpected partners together and building new ways of working collectively," requiring "significant investment in the quality of participation with a capacity development lens." De Silva et al. (2014) faced challenges of operationalizing true ownership during the ToC map development process of a complex healthcare intervention, stating that "although stakeholders provided the context, the map itself was created and 'owned' by the researchers throughout the process" (p. 7).

\section{Supported evidence}

Not unique to ToCs, full participation is not feasible in all cases (Breuer et al., 2016). The type of participant (e.g., staff, partners, community members), the extent of participation (e.g., consultative, participatory, locally led), and method of engagement (e.g., informal meetings, workshops, interviews) will depend on the purposes of the ToC. Furthermore, as developed pathways might not be universally beneficial (and, conversely, socially exclusionary), evaluators need to consider what experiences are left unexplored, and the implications of this (Forsyth, 2018). Working together to theorize the program, develop data-collection systems, and test theories will also be challenging (Weiss, 1995); several authors, for example, reported difficulties in clarifying linkages and causal assumptions behind them during the participatory ToC process (e.g., Archibald et al., 2016; Belcher et al., 2017; Omore et al., 2019). While evaluators can foster quality participation (Apgar et al., 2017), successful ToCs will require a level of preparedness and critical thinking on the parts of users to engage in a process of reflective learning with evaluators (Mason \& Barnes, 2007; Vogel, 2012). It will also require funders to not only be looking at evaluators to simply present them with evidence of what works, but be open to learning about the circumstances in which programs work, why, and how.

\section{Concern 6. Neglecting context}

Many ToCs are problematic in that they specify mechanisms linking activities to outcomes but pay little attention to how these mechanisms function across time and space (Blamey \& Mackenzie, 2007; Green, 2017; Moore \& Evans, 2017).

\section{Partly supported evidence}

While practitioners should demonstrate a clear understanding of how the problem under consideration is created and sustained in context, ToCs to date have been slow in response. A systematic review found that few papers using ToCs for developing public health interventions explicitly explored the influence of context on the intervention (Breuer et al., 2016). Yet it is increasingly recognized that interventions cannot be separated from existing systems in which they are 
introduced. Indeed, substantial efforts are being made to integrate context into ToCs. In James (2011), the definition of ToC has been expanded to be "an ongoing process of reflection to explore change and how it happens-and what that means for the part we play in a particular context, sector and/or group of people" (James, 2011, p. 27; emphasis added). A good example of a context-informed ToC is provided in Mason and Barnes (2007), where the ToC development process of a preventative services program involved "an emphasis on understanding the context within which the initiative operates, recognizing that context may change and may impact upon activities and hence outcomes" (p. 156). One study adopted a ToC approach and found that a focus on context, mechanisms, and outcome relationships provided a useful way for evaluators to track and monitor the resources offered to make a program work (Maye et al., 2019).

\section{Concern 7. Overlooking complexity}

Despite its emphasis on complexity, the presentation of ToCs tends to oversimplify real-world challenges (Armitage et al., 2019; Dhillon \& Vaca, 2018; Ghate, 2018) or inadequately consider systems in which an initiative is introduced (Maini et al., 2018). Furthermore, while many ToCs aim to examine the causal relationships among activities, outputs, and outcomes, they often proceed in a linear fashion, leading to some practitioners coming to view ToC as a "glorified logframe" (James, 2011, p. 10). The limited feedback loops also imply a process of change that has a linear trajectory (Davies, 2018). This linearity makes it difficult for ToCs to capture complexity and unexpected outcomes (Leeuw \& Donaldson, 2015).

\section{Supported evidence}

Linearity is perhaps influenced by early conceptualizations of theory-driven evaluation that tended to use linear models (Weiss, 1997). Theory-driven evaluation is an umbrella term covering ToCs and other approaches to evaluation based on constructing program theories. While the process of developing a ToC may be seen as overly linear, linearity has the advantage of relative simplicity. And compared to other evaluation approaches, ToCs encourage practitioners to think more systematically by emphasizing the unpacking and testing of core assumptions (Armitage et al., 2019). Nevertheless, authors argue ToCs evaluating complex interventions could do more in "understanding how the intervention relates to and interacts with components of the system to produce an effect" (Maini et al., 2018, p. 1). Indeed, complexity can be defined as "a property of the intervention and the context/system into which an intervention is placed" (Hawe, 2015, p. 317). A complex intervention is composed of multiple interacting components, whereas a complex system is one that is adaptive to changes in its local environment, is composed of other complex systems, and behaves in a non-linear fashion (Shiell, Hawe, \& Gold, 2008). Several studies provided insights into addressing complexity (Douthwaite et al., 2017; Douthwaite \& Hoffecker, 2017; Maye et al., 2019); in the context of interventions in complex settings, Douthwaite et al. (2017, p. 206) encouraged "staff to be much more engaged in measuring and analyzing that 
might otherwise be the case. There is also the need to be flexible, adapting and responding to conditions and events as they unfold over time and greater understanding is gained." Ghate $(2018$, p. 5) recommended that ToCs accommodate the concept of emergence, defined as "the unpredictable results of human beings interacting with one another and with the structures and systems that surround them." These suggestions also resonate with outcome harvesting, whereby outcomes are determined a posteriori, thus allowing unpredictable and emerging outcomes to be captured systematically.

\section{DISCUSSION}

This article identifies, characterizes, and evaluates concerns over the use of ToCs in evaluation. Based on the review, some of these concerns are found weakly justified, but others pose valid challenges to ToC research and practice. These challenges focus mostly on how ToC has been operationalized rather than fundamental shortcomings of ToC per se. As such, these concerns do not dismiss the need for ToCs. Rather, they question how far ToC processes go in supporting reflection and learning. In the discussion, opportunities are identified to address ToC concerns and move ToC research and practice forward.

The first two concerns (distinguishing ToCs from other evaluation approaches and conceptual vagueness) can be addressed through clarification from the evaluation team. It is not uncommon, for example, for ToCs to resemble logic models, logical frameworks, and impact pathways, as ToCs were developed as an extension of (and in response to the limitations of) these approaches (Paina et al., 2017). Furthermore, there will likely be confusion among stakeholders, as ToC is not, in fact, a theory as is commonly understood in the social sciences. As such, evaluators should be prepared to explain how ToC compares to other evaluation approaches (e.g., see Prinsen \& Nijhof, 2015) and how ToC differs from social science theories (e.g., see De Silva et al., 2014).

The third concern highlights the limited development of many ToCs. For example, exploring several policy-relevant research activities, Belcher et al. (2017, p. 11) found that "the ToCs developed in these cases are still somewhat crude in their assumptions about the mechanisms of change and about external conditions." The authors explained, "This reflects the fact that our understanding and ability to model knowledge translation, policy change, and social change generally, is still not well developed." Gilissen et al. (2018) expressed similar sentiments that there is not enough information about the effectiveness of separate components. However, the authors acknowledged that as programs unfold, ToCs are expected to become more sophisticated and increasingly accurate in their assumptions. Thus, ToC development should be revisited following learning from implementation and contributions from the literature.

The fourth concern emphasizes the potential for ToCs to both inform and be informed by behavioural change theories. It is likely that the multiple components of an initiative as a whole might not be generalizable, but the individual 
mechanisms behind the behaviour change are. By testing such mechanisms of change, ToC can contribute to our understanding of and ability to model behavioural change interventions (De Silva et al., 2014; Mayne, 2015, 2017). Doing so also facilitates the development of assumptions and external conditions. As for ToCs being informed by theory, Weiss (1997, p. 51) encouraged evaluators to "look at the social sciences, including social psychology, economics, and organization studies, for clues to more valid formulations, as they have to become better versed in theory development themselves." Indeed, Archibald et al. (2016, p. 3) questioned "whether it is even reasonable to talk about theories of change if the theoretical bases for a model's construction are not well founded in the context and conditions to which it is being applied." Drawing on existing theories supports evaluators and participants in encouraging the articulation of ToCs (Mason \& Barnes, 2007).

The fifth concern relates to how, to what extent, and which stakeholders will be engaged in ToC development. Overall, stakeholder engagement will depend on the purposes of the ToC. If, for example, the primary purpose is to co-create a shared roadmap toward addressing a collectively experienced problem, it might be important to engage a broad range of stakeholders. And engaging in partnerships rather than consultations might help facilitate ownership in the process and continued interest during revision stages. However, if the main purpose is to identify how, why, and in what context a specific program is intended to work, perhaps working with the core program team would be sufficient. Besides the general encouragement that diverse stakeholders should be engaged in ToC development, there is limited practical guidance on what this process looks like in practice; reflecting on and sharing experiences of stakeholder engagement is important for supporting future ToC implementation.

The last two concerns (incorporating context and capturing complexity) relate to ToC implementation. Understanding how initiatives relate to context is key to understanding how they work; not taking into account such relationships is a reason why many initiatives shown to work in one setting fail to achieve similar outcomes elsewhere. Yet, context is often neglected in ToC maps. To address the limited considerations of context, ToC maps should provide important insights into the circumstances in which a program works while its corresponding narrative elaborates on the details. Ghate (2018) also recommended the assessment of root causes of the specific problem to be included in a ToC that encourages participants "to recognize the intervention in its systemic context and to see it as one part of the wider picture of the impetus for change" (p. 4). Realist evaluation, another theory-driven approach to evaluation, can support this assessment by focusing on the context under which change occurs (Douthwaite et al., 2017; Pawson, 2013; Rolfe, 2019). Finally, ToCs often fail to represent complexity in its visual representation, despite being espoused to support complex initiatives. ToCs could be enhanced by being visualized as dynamic and interactive, with multiple pathways to results and multiple feedback loops; by varying the sizes, shapes, and colours of ToC elements to portray differences in significance among activities, 
outputs, and outcomes; and by formatting the arrows to specify the nature of connections (e.g., which are based on strong evidence compared to others that require further testing).

Taken together, these opportunities could move ToC use from a one-off activity exploring change pathways to facilitating ongoing learning about theories, context, and complexity inherent within change pathways. In the future, it is important to develop quality assurance in the reporting on ToCs. Based on a systematic review of the published literature on ToCs for public health interventions, Breuer et al. (2016) offered a checklist for reporting ToCs that capture context, stakeholder engagement, and assumptions. And in Armitage et al. (2019), standards are offered (e.g., equity, governance) to support the assessment of a successful ToC. Based on this review, quality in ToCs also depends on its ability to capture complexity and contribute to broader theories. Opportunities for future research on ToCs include exploring how ToCs operate across space, scales, and sectors; how ToCs compare from one similar program to another; and how ToCs can contribute to the identification of shared mechanisms of change. This has already begun in some cases where, for example, generic ToCs have been produced (Mayne \& Johnson, 2015). There is a need, however, for research at the regional/ national scales to complement the community-level work that has proliferated to date, with nested ToCs proposed as one way of developing ToCs at multiple scales (Mayne, 2015).

\section{CONCLUSION}

ToC encourages us to ask critical questions such as how, why, and in what context a program works by directing attention to outcomes, change pathways, and assumptions. Doing so represents a new way of thinking for many, leading to challenges in ToC operationalization and potential for learning. By critically engaging with the literature on discontents of ToC, opportunities have been identified to support learning from the ToC process. At the conceptual level, opportunities include clarifying what exactly is a ToC and how it differs from other evaluation approaches and social science theories. At the methodological level, it is important to integrate context and complexity throughout the ToC process, contribute not only to programming-specific knowledge but also broader theoretical knowledge, and practice thoughtfulness into the level of stakeholder engagement required and the implications of this. Finally, ToCs should be adapted as new information is gained, not only from the unfolding of initiatives but also from developments in ideas, concepts, and methods of ToC.

\section{ACKNOWLEDGEMENTS}

The author appreciates the 2019 Canadian Evaluation Society conference attendees for fruitful conversations that motivated this work. He thanks the two anonymous reviewers for their thoughtful comments. He thanks Daniel Cockayne for providing helpful feedback on earlier versions of this paper. 


\section{NOTE}

1 Helpful examples and definitions of the elements of a ToC are provided by the Center for Theory of Change (www.theoryofchange.org), created by ActKnowledge, one of the pioneers in the conceptual development of ToCs.

\section{REFERENCES}

Amundsen, C., \& D’Amico, L. (2019). Using Theory of Change to evaluate socially-situated, inquiry-based academic professional development. Studies in Educational Evaluation, 61, 196-208. https://doi.org/10.1016/j.stueduc.2019.04.002

Apgar, J. M., Allen, W., Albert, J., Douthwaite, B., Ybarnegaray, R. P., \& Lunda, J. (2017). Getting beneath the surface in program planning, monitoring and evaluation: Learning from use of participatory action research and theory of change in the CGIAR Research Program on Aquatic Agricultural Systems. Action Research, 15(1), 15-34. https://doi.org/10.1177/1476750316673879

Archibald, T., Sharrock, G., Buckley, J., \& Cook, N. (2016). Assumptions, conjectures, and other miracles: The application of evaluative thinking to theory of change models in community development. Evaluation and Program Planning, 59, 119-127. https://doi. org/10.1016/j.evalprogplan.2016.05.015. Medline:27324286

Armitage, D., Arends, J., Barlow, N. L., Closs, A., Cloutis, G. A., and Cowley, M. S., . . Wiens, C. (2019). Applying a "theory of change" process to facilitate transdisciplinary sustainability education. Ecology and Society, 24(3). https://doi.org/10.5751/es-11121-240320

Belcher, B., Suryadarma, D., \& Halimanjaya, A. (2017). Evaluating policy-relevant research: Lessons from a series of theory-based outcomes assessments. Palgrave Communications, 3(1). https://doi.org/10.1057/palcomms.2017.17

Blamey, A., \& Mackenzie, M. (2007). Theories of change and realistic evaluation: Peas in a pod or apples and oranges? Evaluation, 13(4), 439-455. https://doi.org/10.1177/ 1356389007082129

Breuer, E., Lee, L., De Silva, M., \& Lund, C. (2016). Using theory of change to design and evaluate public health interventions: A systematic review. Implementation Science, 11(1). https://doi.org/10.1186/s13012-016-0422-6. Medline:27153985

Connell, J. P., \& Kubisch, A. C. (1998). Applying a theory of change approach to the evaluation of comprehensive community initiatives: Progress, prospects, and problems. Theory Measurement and Analysis, 2, 15-44.

Davies, R. (2018). Representing theories of change: Technical challenges with evaluation consequences. Journal of Development Effectiveness, 10(4), 438-461. https://doi.org/1 $0.1080 / 19439342.2018 .1526202$

Davis, R., Campbell, R., Hildon, Z., Hobbs, L., \& Michie, S. (2015). Theories of behaviour and behaviour change across the social and behavioural sciences: A scoping review. Health Psychology Review, 9(3), 323-344. https://doi.org/10.1080/17437199.2014.94 1722. Medline:25104107

De Silva, M. J., Breuer, E., Lee, L., Asher, L., Chowdhary, N., Lund, C., \& Patel, V. (2014). Theory of Change: A theory-driven approach to enhance the Medical Research Council's framework for complex interventions. Trials, 15(1). https://doi.org/10.1186/17456215-15-267. Medline:24996765 
Dhillon, L., \& Vaca, S. (2018). Refining theories of change. Journal of MultiDisciplinary Evaluation, 14(30), 64-87.

Douthwaite, B., \& Hoffecker, E. (2017). Towards a complexity-aware theory of change for participatory research programs working within agricultural innovation systems. Agricultural Systems, 155, 88-102. https://doi.org/10.1016/j.agsy.2017.04.002

Douthwaite, B., Mayne, J., McDougall, C., \& Paz-Ybarnegaray, R. (2017). Evaluating complex interventions: A theory-driven realist-informed approach. Evaluation, 23(3), 294-311. https://doi.org/10.1177/1356389017714382

DuBow, W. M., \& Litzler, E. (2019). The development and use of a theory of change to align programs and evaluation in a complex, national initiative. American Journal of Evaluation, 40(2), 231-248. https://doi.org/10.1177/1098214018778132

Forsyth, T. (2018). Is resilience to climate change socially inclusive? Investigating theories of change processes in Myanmar. World Development, 111, 13-26. https://doi. org/10.1016/j.worlddev.2018.06.023

Freer, G., \& Lemire, S. (2019). Can't see the wood for the logframe: Integrating logframes and theories of change in development evaluation. Canadian Journal of Program Evaluation, 33(3), 336-353. https://doi.org/10.3138/cjpe.53007

Funnell, S. C., \& Rogers, P. J. (2011). Purposeful program theory: Effective use of theories of change and logic models. San Francisco, CA: Jossey-Bass.

Ghate, D. (2018). Developing theories of change for social programmes: Co-producing evidence-supported quality improvement. Palgrave Communications, 4(1). https:// doi.org/10.1057/s41599-018-0139-z

Gilissen, J., Pivodic, L., Gastmans, C., Stichele, R. V., Deliens, L., Breuer, E., \& Van den Block, L. (2018). How to achieve the desired outcomes of advance care planning in nursing homes: A theory of change. BMC Geriatrics, 18, 47. https://doi.org/10.1186/ s12877-018-0723-5

Green, D. (2017). Theories of change for promoting empowerment and accountability in fragile and conflict-affected settings. Brighton, England: Institute of Development Studies.

Hawe, P. (2015). Lessons from complex interventions to improve health. Annual Review of Public Health, 36(1), 307-323. https://doi.org/10.1146/annurev-publhealth031912-114421. Medline:25581153

Hivos. (2015). Theory of change thinking in practice. The Hague, Netherlands: Hivos.

James, C. (2011). Theory of change review: A report commissioned by Comic Relief. London, England: Comic Relief.

Leeuw, F. L., \& Donaldson, S. I. (2015). Theory in evaluation: Reducing confusion and encouraging debate. Evaluation, 21(4), 467-480. https://doi.org/10.1177/1356389015607712

Maini, R., Mounier-Jack, S., \& Borghi, J. (2018). How to and how not to develop a theory of change to evaluate a complex intervention: Reflections on an experience in the Democratic Republic of Congo. BMJ Global Health, 3(1), e000617. https://doi.org/10.1136/ bmjgh-2017-000617. Medline:29515919

Makowiecka, K., Marchant, T., Betemariam, W., Chaturvedi, A., Jana, L., Liman, A., . . Schellenberg, J. (2019). Characterising innovations in maternal and newborn health 
based on a common theory of change: Lessons from developing and applying a characterisation framework in Nigeria, Ethiopia and India. BMJ Global Health, 4(4), e001405. https://doi.org/10.1136/bmjgh-2019-001405. Medline:31406587

Maru, Y. T., Sparrow, A., Butler, J. R. A., Banerjee, O., Ison, R., Hall, A., \& Carberry, P. (2018). Towards appropriate mainstreaming of "Theory of Change" approaches into agricultural research for development: Challenges and opportunities. Agricultural Systems, 165, 344-353. https://doi.org/10.1016/j.agsy.2018.04.010. Medline:32287945

Mason, P., \& Barnes, M. (2007). Constructing theories of change: Methods and sources. Evaluation, 13(2), 151-170. https://doi.org/10.1177/1356389007075221

Maye, D., Enticott, G., \& Naylor, R. (2019). Theories of change in rural policy evaluation. Sociologia Ruralis, 60(1), 198-221. https://doi.org/10.1111/soru.12269

Mayne, J. (2015). Useful theory of change models. Canadian Journal of Program Evaluation, 30(2), 119-142. https://doi.org/10.3138/cjpe.230

Mayne, J. (2017). Theory of change analysis: Building robust theories of change. Canadian Journal of Program Evaluation, 32(2), 155-173. https://doi.org/10.3138/cjpe.31122

Mayne, J., \& Johnson, N. (2015). Using theories of change in the CGIAR Research Program on Agriculture for Nutrition and Health. Evaluation, 21(4), 407-428. https://doi. org/10.1177/1356389015605198

Moore, G. F., \& Evans, R. E. (2017). What theory, for whom and in which context? Reflections on the application of theory in the development and evaluation of complex population health interventions. SSM-Population Health, 3, 132-135. https://doi. org/10.1016/j.ssmph.2016.12.005. Medline:29302610

Nilsen, P. (2015). Making sense of implementation theories, models and frameworks. Implementation Science, 10(1), 53. https://doi.org/10.1186/s13012-015-0242-0. Medline:25895742

Nkwake, A. M. (2013). Working with assumptions in international development program evaluation. New York, NY: Springer. https://doi.org/10.1007/978-1-4614-4797-9

Omore, A., Kidoido, M., Twine, E., Kurwijila, L., O’Flynn, M., \& Githinji, J. (2019). Using "theory of change" to improve agricultural research: Recent experience from Tanzania. Development in Practice, 29(7), 898-911. https://doi.org/10.1080/09614524.201 9.1641182

Paina, L., Wilkinson, A., Tetui, M., Ekirapa-Kiracho, E., Barman, D., Ahmed, T., .. . Bennett, S. (2017). Using Theories of Change to inform implementation of health systems research and innovation: Experiences of future health systems consortium partners in Bangladesh, India and Uganda. Health Research Policy and Systems, 15(S2). https:// doi.org/10.1186/s12961-017-0272-y. Medline:29297374

Pawson, R. (2013). The science of evaluation: A realist manifesto. London, England: SAGE.

Prinsen, G., \& Nijhof, S. (2015). Between logframes and theory of change: Reviewing debates and a practical experience. Development in Practice, 25(2), 234-246. https://doi. org/10.1080/09614524.2015.1003532

Rolfe, S. (2019). Combining Theories of Change and Realist Evaluation in practice: Lessons from a research on evaluation study. Evaluation, 25(3), 294-316. https://doi.org/ $10.1177 / 1356389019835229$ 
Sarma, H., Budden, A., Luies, S. K., Lim, S. S., Shamsuzzaman, M., Sultana, T., . . Uddin, M. J. (2019). Implementation of the World's largest measles-rubella mass vaccination campaign in Bangladesh: A process evaluation. BMC Public Health, 19(1), 925. https:// doi.org/10.1186/s12889-019-7176-4. Medline:31291922

Shiell, A., Hawe, P., \& Gold, L. (2008). Complex interventions or complex systems? Implications for health economic evaluation. British Medical Journal, 336(7656), 1281-1283. https://doi.org/10.1136/bmj.39569.510521.ad. Medline:18535071

Stein, D., \& Valters, C. (2012). Understanding theory of change in international development. London, England: Justice and Security Research Programme.

Thompson, G. H., \& Moret, W. (2019). Building a theory of change for community development and HIV programming: The impact of social capital, stigma reduction and community-level changes on HIV-related health outcomes for orphans and vulnerable households in Mozambique. Community Development, 50(3), 332-351. https:// doi.org/10.1080/15575330.2019.1606839

Valters, C. (2015). Theories of change: Time for a radical approach to learning in development. London, England: Overseas Development Institute.

Vogel, I. (2012). Review of the use of 'theory of change' in international development. London, England: UK Department for International Development.

Weiss, C. H. (1995). Nothing as practical as good theory: Exploring theory-based evaluation for comprehensive community initiatives for children and families. New Approaches to Evaluating Community Initiatives: Concepts, Methods, and Contexts, 7 , 65-92. https://doi.org/10.1177/1356389003094007

Weiss, C. H. (1997). Theory-based evaluation: Past, present, and future. New Directions for Evaluation, 1997(76), 41-55. https://doi.org/10.1002/ev.1086

\section{AUTHOR INFORMATION}

Steven Lam is an independent researcher and evaluator with professional experience in public health, agriculture, food security, climate change, and international development fields. Drawing on theory-driven, feminist, and developmental approaches to evaluation, he supports organizations in learning from and adapting their programs. He is particularly interested in encouraging reflective practice to produce better evaluations. 